\title{
Magnetic multidirectional anchor-guided endoscopic submucosal tunnel dissection for large gastric lesions
}

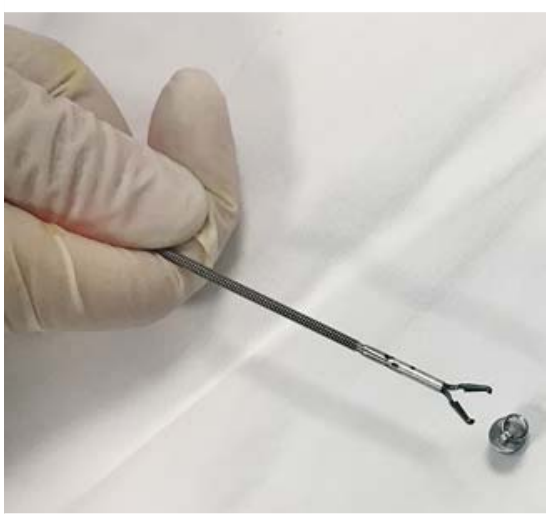

- Fig. 1 Photograph of the iron-shelled magnet, which is attached to a hemoclip with dental floss.

Magnetic anchor-guided endoscopic submucosal dissection (MAG-ESD) using an extracorporeal electromagnet was developed to provide excellent visualization and to facilitate complicated ESD in patients with early gastric cancer (EGC), with its use being reported in several studies over recent years [1-3]. Endoscopic submucosal tunnel dissection (ESTD) has been reported as a treatment for the en bloc dissection of large early neoplastic lesions with higher dissection speed and better radical cure rates than standard ESD $[4,5]$. This case report describes a new method, magnetic multidirectional anchor-guided ESTD (MMAGESTD), for the treatment of large EGCs in human subjects.

A 54-year-old woman was referred to our hospital with a high grade intraepithelial neoplasia extending from the gastric angle to the fundus. MMAG-ESTD was performed using a gastroscope fitted with a soft transparent front cap. The magnetic anchor-guided system consists of an interior magnet made of an Nd2Fe14B crystal, with a shell of pure iron, and an internal device, which is a medical stainless steel column of $10 \times 10 \mathrm{~mm}$ ( $\triangleright$ Fig. $\mathbf{1}$ ).

After a partial mucosa cut was made transversely with a DualKnife, one magnetic anchor consisting of an internal neodymium magnet with a hemoclip was attached to the proximal mucosal edge of the lesion ( $\triangleright$ Fig. 2 a). A submucosal tunnel was then created by submucosal dissection from the proximal to the distal end. Unlike previous magnetic devices, this system requires no external magnets, which makes the entire procedure simpler. The other two shells with hemoclips were attached to the horizontal mucosal edge, which then attracted the internal magnet, with adequate countertraction to create good visualization, thereby assisting the submucosal dissection procedure ( $\mathbf{F i g} \mathbf{2} \mathbf{b}$ ). The mucosal countertraction fully exposed the submucosal field of vision in three directions. MMAG-ESTD was successful performed without adverse events (> Fig. 2 c; $>$ Video 1).

By combining the advantages of both magnetic ESD and tunnel ESD, we hope that this MMAG-ESTD system will facilitate difficult ESD procedures and enhance the field of magnetic endoscopic surgery in future.

Endoscopy_UCTN_Code_TTT_1AO_2AG

Competing interests

The authors declare that they have no conflict of interest.
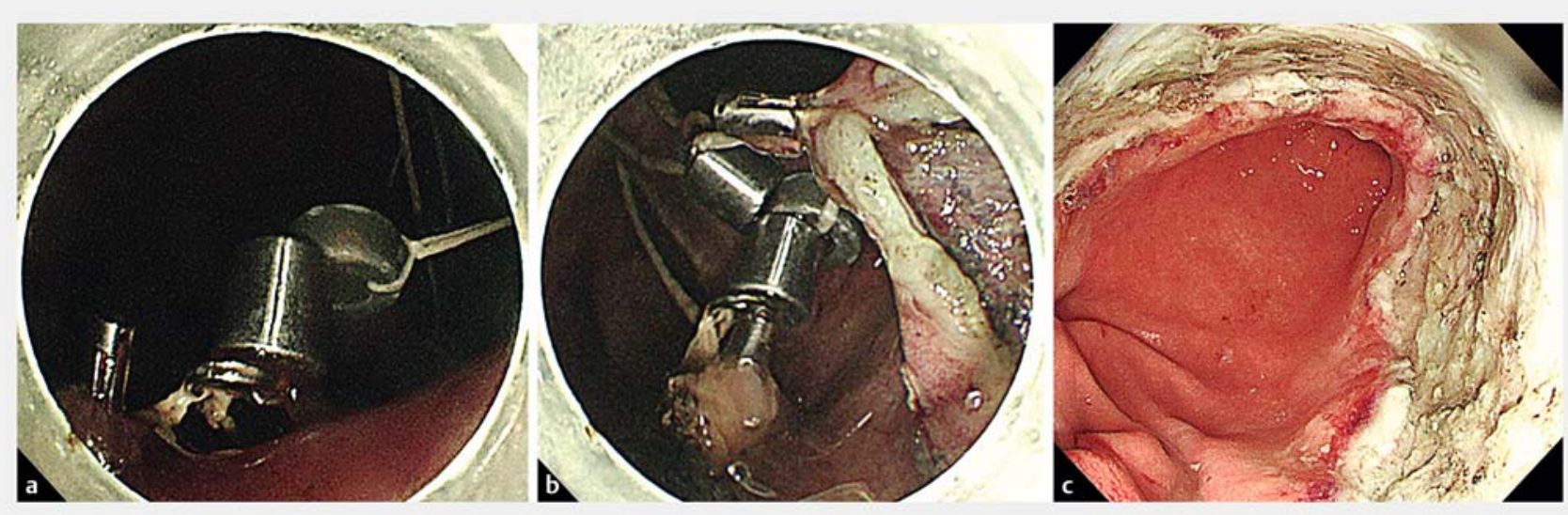

- Fig. 2 Endoscopic views showing: a after partial dissection, the mucosal edge with the magnetic anchor attached; $\mathbf{b}$ direct visualization of the submucosal layer that is achieved by traction via the magnetic shells; $\mathbf{c}$ the large artificial ulcer left after magnetic multidirectional anchorguided endoscopic submucosal tunnel dissection. 


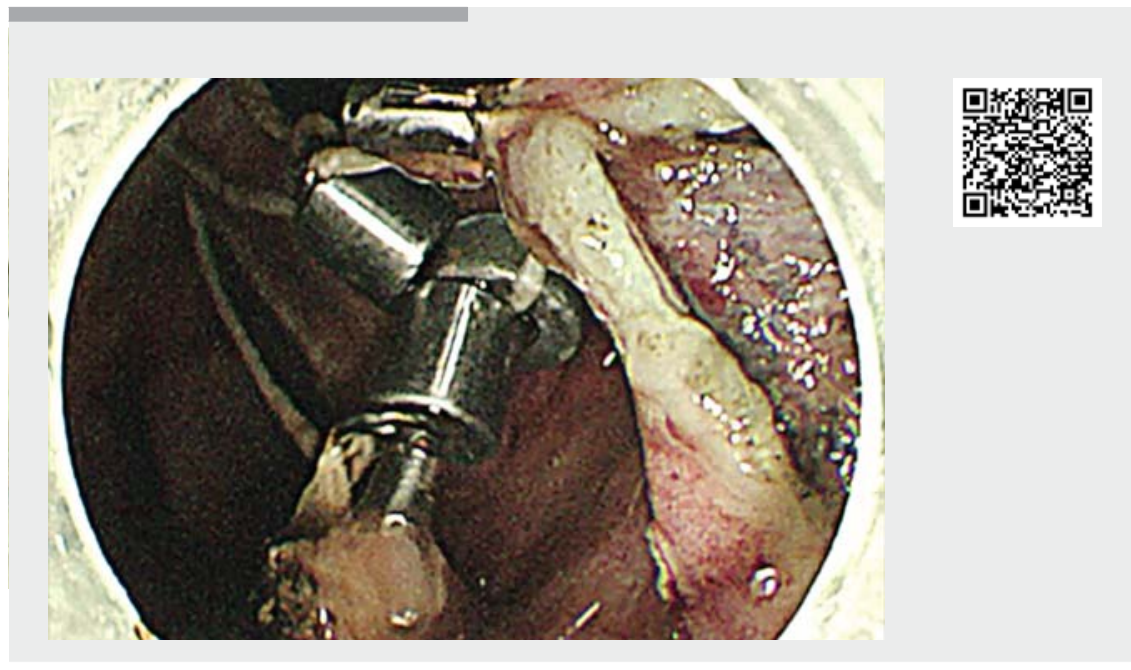

Video 1 Magnetic multidirectional anchor-guided endoscopic submucosal tunnel dissection is performed for a large gastric lesion.

The authors

Shengzhen Liu ${ }^{1,}{ }^{*}$, Yichao Chai ${ }^{2,{ }^{*}, \text { Enqiang }}$ Linghu' ${ }^{1}$, Bo Zhang ${ }^{1}$, Ningli Chai ${ }^{1}$, Yi Lv ${ }^{2}$

1 Department of Gastroenterology and Hepatology, Chinese PLA General Hospital, Xi'an, P.R. China

2 Department of Oncology, The Second Affiliated Hospital of Xi'an Jiaotong University, Xi'an, P.R. China

\section{Corresponding author}

\section{Ningli Chai, MD}

Department of Gastroenterology and Hepatology, Chinese PLA General Hospital, 28 Fuxing Road, Haidian District, Beijing 100853, China

chainingli@vip.163.com

\section{References}

[1] Mortagy M, Mehta N, Parsi MA et al. Magnetic anchor guidance for endoscopic submucosal dissection and other endoscopic procedures. World J Gastroenterol 2017; 23 : 2883-2890

[2] Matsuzaki I, Hattori M, Hirose K et al. Magnetic anchor-guided endoscopic submucosal dissection for gastric lesions (with video). Gastrointest Endosc 2018; 87: 1576-1580

[3] Matsuzaki I, Hattori M, Yamauchi H et al. Magnetic anchor-guided endoscopic submucosal dissection for colorectal tumors (with video). Surg Endosc 2020; 34: 10121018

[4] Zhang X, Shi D, Yu Z et al. A multicenter retrospective study of endoscopic submucosal tunnel dissection for large lesser gastric curvature superficial neoplasms. Surg Endosc 2019; 33: 1910-1919

[5] Linghu E, Feng X, Wang X et al. Endoscopic submucosal tunnel dissection for large esophageal neoplastic lesions. Endoscopy 2013; 45: 60-62

\section{Bibliography}

Endoscopy 2021; 53: E382-E383

DOI 10.1055/a-1298-3984

ISSN 0013-726X

published online 9.12.2020

(c) 2020. Thieme. All rights reserved.

Georg Thieme Verlag KG, Rüdigerstraße 14, 70469 Stuttgart, Germany

\section{ENDOSCOPY E-VIDEOS}

https://eref.thieme.de/e-videos

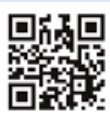

Endoscopy E-Videos is a free access online section, reporting on interesting cases and new

techniques in gastroenterological endoscopy. All papers include a high quality video and all contributions are freely accessible online.

This section has its own submission website at https://mc.manuscriptcentral.com/e-videos

\footnotetext{
* Co-first authors and contributed equally to this work
} 